in my absence, informs me that he considered the case mast suecessful.

The last case was that of a poor Smyrna Jew, who had had exfoliation of the upper margin of the orbit; and as he had not had the advantage of medical advice, the progress of the case had been very protracted. The deformity was very great, and the surrounding tissues much indurated and scarred. He was decidedly strumons, and constantly suffering from ophthalmia, by which the transparency of the cornea had been greatly destpoyed, so that scarcely any vision remained. With the assistance of my colleague, Mr. Holthouse, I repeated nearly the same operation as the last, the patient being under the influence of chloroform.

The difficulty of obtaining sufficient covering, in this case, Was much greater, as the cartilage had dwindled into a mere ring, and the indurated skin was less manageable; still, I be. lieve, the improvement quite equalled that which could have been obtained by any other means, as far as I could judye, and the improvement of the condition of the cornea continued, while under my care; but as I left for the Crimea within a few weeks after the operation, I am not able to give any further account of him.

The above eases no doubt might have been more or less relieved by the usual operations; but I believe the lid was more effactually liberated by the course pursued than could easily have been accomplished by other means; and as the cartilage must be the basis of the borrowed tissue, the more that important strueture could be replaced the greater the resulting success. In all, the scars of incisions were awoided, and the minimum of injury to the tissues (compatible with success) inflicted. It is obvious that the plan is only applicable to those cases in which the tarsus remains, the deformity being due to the condition of the integument. If it possess any merit over other proceedings in similar cases, it is aseribable to its freedom from the resulting deformity of vertical incisions, or the scars consequent on transplanting integument.

Linshury-square, 1857.

\section{NOTES OF}

\section{CASES OF RUPTURED PERINAUM.} WTTH REMARKS.

BY I. BAKER BROWN, EsQ, F.R.C.S. (by Exam.,) \&c., SUBGEON-ACCOECHEVR TIO FT. MART'S HOSPITAX.

(Concluded from p. 217.)

CASE 11-MrS. D - aged thirty; complete laceration of the sphincter of two years' durition; operation; cure.-This patient came from Baltimore, United States, to consult me. Nothing particular oecurred during her first four confinements, but in the fifth the head became impacted, and forceps were applied. During the passage of the head the peringum gave way from behind forwards. She was operated upon aubse. quently by Dr. Buckler, when everything promised well, until the bowels were moved, when the recently united parts gave way. She was then as bad as ever. The freces passed involuntarily.

Nov. 20th, 1856. -I operated in the usual way, assisted by Messrs. Musgrave, Britton, G. Brown, and Philip Harper.

22nd.-.Removed the deep sutures. Slight ulcerative tendency of the tracks.

23rd.- Removed the superficial.sutures.

Dec. Ist.-Bowels moved.

16th.-Quite well.

Remarks. - From the sphincter having been thoroughly divided at the frrst operation the sphincter action is not so strong as usual; but this, time will quite cure. The patient left London, five weeks after the operation, for a tour on the continent, before returning to Baltimore.

CASE 12.-Mrs. P_- aged forty-one; laceration of perinieum, but not throngh the posterior fibres of the sphincter, of eight years' duration; operation; cure - Mother of eleven children. Labours always severe, from the size of the child. When in labour with her eighth child the perinæum gave way at the moment of passage of the head. Prolapsus of the uterus has come on, and much incrensed her sufferings.

Dec. 8 th. - I performed my usual operation, in the presence of Messrs. Hutchinson, Britton, and Mhilip Harper.

10th.-Deep sutures removed, Slight marks of ulceration in their tracks. 12th. - Superficial sutures removed.

14th. - Bowels moved.

24th. - Quite cured.

Remarks. - In this patient the improvement of health generally, and the support and comfort locally, are most marked.

CASE 13.-A. M-; complete laceration of the sphincter, of seven months' duration; operation; cure.

Admitted into Boynton ward, under Mr. Baker Brown, on Oet. 7th, 1856. Was confined of her first child (a male) on March 30 th, by a midwife. On the following day she discovered that she had entirely lost control over her bowels. This has continued ever since.

Oct. 8th. - I performed my usual operation.

11th. - Deep sutures removed.

13th. - Superficial sutures removed. Catamenia appeared.

19th. - Bowels moved.

30th.- Discharged, quite cured.

Remarls. - It will be gen that this case, although one of severe rupture, was cured, and the patient discharged, in le\$s than a month.

CASE 14.-S. C-_ ; laceration of perinæum, and lass of twe inches of rectum, of seven months' duration; operation; relief.

Admitted into Boynton ward, under Mr. Baker Brown, on Sept. 11th, 1856. She was delivered of a large male child on Jan. 28th, by the aid of instruments. Three days afterwards she had a dose of castor oil, which acted with comparative comfort. Five days afterwards the motions were passed through the vagina. She suffered most excruciating pain. About four months before her confinement she had severe pain. in the lumbar region, with frequent desire to em ty the rectum, attended with great agony and a discharge of blood and pus. This continued until labour began. On examination it was found that a portion of superficial perinæum was left, and fully two inches of the rectum had sloughed away; and at the commencement of the sound rectum there was almost $\rho$ firm cartilaginous ring, barely allowing the end of the finger to be pressed through.

Sept. 13th. - The perineal band, with some fibres of tha sphincter ani, were divided. This relieved the patient in passing her motions.

Oct. 29th.-Mr. Brown divided, by subcutanoous incision, theentire coccygeal attachments of the sphineter and levator ani.

Nov. 4th. - Bowels opened to-day, with perfect freedom from pain, more than she had known for the last sixteen months.

Remarlis. - It was quite impassible to do any mare for this poor patient. No amount of ingenuity could make a new perinæum.

CASE 15. - L. B-, aged forty-eight; complete lacepation through the sphineter of twenty-one years' duration; operation; relief; second operation; cure.

Admitted into Boynton ward, under Mr. Baker Brown, op Oct. 21st, 1856. Has had eleven children. Was confined of her first twenty-one years ago, after a tedious labour. She had no control over the bowels after that time. Each successive labour appeared to make matters worse.

Oct. 22 nd. - I performed my usual operation.

24th. - Fever and diarrhoea came on, which necessitated the removal of all the sutures, and of course materially arrested union of the parts.

27 th. - Catamenia appeared.

After many days of diarrhoea, she gradually recovered, and left the hospital, on Dec. 10th, with partial union and abilitis to hold the motions when the bowels are not relaxed, and then some fæces pass through the recto-vaginal opening.

She was re-admitted on Jan. 13th, 1857, and on Jan. 1.4th, I performed my usual operation de novo.

Jan. 16th. -Deep sutures removed.

24th. - Supericial sutures removed, and the bowels opened. Feb. 21st. - Discharged quite cured.

Remark. - It appeared on inquiry that she had suffered from diarrhœa for four months before entering the haspital; hence the cause of the failure of the first operation.

It will be observed, that of these fifteen cases, twelve were completely and effectually cured; one was partially successful; one was a good deal relieved, though, from the character of the injury, I could not undertake my usual operation; and one was unsuccessful. In all the cases, I wish to mention that there was more or less prolapsus of the nter'us." In some, it descended to the external parts; whilst in others it had not become so severe, but still was present; and in all it adsed most materially to the pain, suffering, and wretched condition of the poor creatures, whose lives were already a misery to themselves and those about them. This confirms me in the opinion I formerly 
expressed, that prolapsus of the uterus was one of the necessary sequences of ruptured perinæum, a fact which was denied in some quarters when I first wrote upon the subject. I wish to make a few remarks upon those cases where the result was unsatisfactory.

First, the unsuccessful case. This woman deceived me about her age. When she first came under my care, she stated it to be fifty-five, but it was proved afterwards to be sixty-five. Further, it was discovered after the operation that she was in the habit of taking large quantities of opium to alleviate her pain, as well as of drinking large quantities of gin. Had I known these facts before the operation, I should not have performed it. The attack of paralysis with which she was seized whilst in the hospital was an additional proof of her broken-up system. There appeared no vigour or power left in her system. The hæmorrhage which took place further weakened her a good deal, and appeared to come on more from want of coagulating power in the blood than from any particular vessel.

Secondly, the partially successful case. This lady was born without any anus, and an operation was performed soon after birth in order to produce one. It consequently was very deeply retracted, (at least two inches above its normal situation, ) and was very small and contracted, as well as irritable. The tendency to prolapse of the bladder was a great disadvantage, and altogether nothing but a strong desire to alleviate somewhat her constant sufferings induced me to attempt an operation. It must further be borne in mind, that the length of time this state had existed had added most materially to the difficulties to be contended with under the peculiar circumstances.

Thirdly, the case of partial relief. This poor woman was in a most miserable condition. Fully two inches of the rectum itself had sloughed away. The permanence of the symptoms of disease in her rectum previous to her confinement showed that there already existed a strong tendency to mischief, which would be aggravated at the time of labour. There was a slight band of superficial perinæum and a few fibres of the sphincter, which appeared to add much to her sufferings, and when I divided them, she was much relieved. It took away the tension of the parts. The entrance into the rectum being closed by an almost cartilaginous ring, which barely allowed the passage of the finger, whilst it showed what Nature under circumstances will do, nevertheless was a further obstacle to relief being obtained. After a most mature consideration of the whole bearings of the case, I determined to divide the sphincter and levator ani muscles from their coccygeal attachmen's, and I did so by subcutaneons incision, as recommended by Mr. Hilton. This allowed the parts to fall into a more natural position, and relieved their state of tension, as well as allowing the fissures to heal and the parts to become more sound. No ingenuity could do more than this for the poor woman. She expressed herself as having much greater comfort and freedom from pain than she had known for a long period.

It will be seen, that if we add these cases to those formerly published, it makes my present number stand thus: forty-seven cases operated upon, of which forty-two were perfectly and entirely successful, two partially successful, one relieved, one unsuccessful, and one death ; or, excluding the case 1 have just considered, and which cannot fairly be classed with my operation, I show forty-six cases, with forty-two perfect cures, or an average of 9130 per cent. This per-centage, large as it is, would, I have no doubt, be much increased. It requires very careful dissection merely to take off enough mucous membrane, for the purpose of making a raw surface, without leaving small pouches in the cellular tissue beneath to become the seats of the ulcerative process. Upon the whole, the results are most satisfactory, as showing how one of the most painful and wretched conditions to which females are liable is now entirely under our control, and can with almost certainty be cured.

Connaught-square, Hyde-park, 1857.

\section{TH E E P I D E M I C.}

\section{By J. PIDDUCK, M.D.}

The successful practice of physic depends upon sound patholing, which is deduced not only from morbicl anatomy, but also from the causes and symptoms of disease.

The cause of the prevailing. epidemic is doubtless atmospheric, though probably telluric in its origin, the emanations 244 being influenced and rendered poisonous by electric agency. Upon this point all are agreed.

The symptoms, the most important part of the pathology, as coming more immediately under the cognizance of our senses and observation, are distinctly those which result from the action of a morbific poison. 'The first or premonitory symptom is epigastric irritation-a dull, depressing pain, with a sense of fulness and soreness, in the stomach and bowels This is followed by nausea, vomiting, and purging, or bilious diarrhoca. If this evacuation of bile by a natural effort be restrained, by stimulants, sedatives, or astringents, bile ceases to be poured out, and the natural efforts continuing, only serous evacuations are passed, constituting the serous diarthoea.

To assert that diarrhœa and cholera are only well-marked stages of the same disease is not quite correct; it is the presence or absence of bile in the evacuations which constitutes the essential difference between them. So long as bile con. tinues to be present in the stools the case is cne of simple diarrhoea, and, if uncomplicated, unattended with danger; but when the diarrhea ceases to be bilious and becomes strous, the case is eminently dangerous.

What is the condition of the alimentary canal which occa sions this marked difference? The answer is supplied by the morbid anatomy of the disease. In the inspection of fatal cases, two most important facts are revealed: a congested state of the mucous membrane of the stomach and duodenum, and a distended state of the gall bladder. That these two states stand in the relation of cause and effect there cannot exist a rational doubt. The congested condition of the mucous membrane lining the duodenum closes the orifice of the bile duct, and prevents the flow of bile.

If this pathological statement of the epidemic be correct, the methods of treating the disease in its invasion by astringents, by stimulants, and by sedatives, on the one hand, and by large and repeated doses of calomel or castor oil-not to mention croton oil and violent drastic purgatives, which is now pretty nearly exploded-on the other, must be equally unphilosophical and dangerous. One danger arises from converting a bilions into a serous diarrhoea; another, from converting a case of diarrhœa into one of bilious typhoid fever. That the same poison which is the cause of diarrhœa is also the cause of bilious typhoid fever, is evident from the fact that cases of both are always rife at the same time, and that the one is convertible into the other by a sudden arrest of the diarrhœea, by which the poison is allowed to enter the blood.

Treatment.-The indications of cure in aid of the natural efforts are, first to dilute, and then to expel the poison. The best diluent is that prescribed by Sydenham-thin meat broth, drank copiously in beci. The safest aperient, and which has answered in a multitude of cases, is haif a grain of calomel and three grains of rhubarb, in a pill, taken immediately after the broth, and followed in three hours by three drachms of castor oil.

In the premonitory stage, this method of cure prevents the access of diarrhœa by at once expelling the poison; and if diarrhoea have already supervened, it serves to carry off the poison and also the bile. which is poured out profusely for its expulsion.

But if the bilious diarrhoea should have been arrested, and should not recur, the case assumes one of two forms equally dangerous-serous diarrhcea or typhoid fever.

In cases of serous diarrhoea, the indications of cure are, to remove the congested state of the mucous membane lining the stomach and duodenum, and to restore the evacuation of bile, To remove the congested state of the mucous membrans, cooling salines, cold drinks, and cold applications to the epigastrium, with warmth to the biliary extremities. To restore the evacuation, the calomel-and-rhubarb pill answers better than more active aperients.

In the treatment of the typhoid fever, since the disease, when once fully formed, runs a definite course, the object is to conduct the patient througn its several stages in safety, by meeting dangerous symptoms as they arise, taking care not to arrest the attendant diarrbcea, only to restrain its excess.

This brief statement is the result of a careful observance of every return of the epidemic from its first appearance in 1831-2 to the present time, a period of twenty-five years, during which I have had extensive opportunities, in private and dispensary practice, of testing the truth of the pathology and the success of the practice. The motto to guide us in the treatment of this and every other epidemic is, obsta principiis. If the golden opportunity be lost, or the case be mismanaged at the outset, it quickly assumes a formidable aspect, and becomes extremely difficult of cure.

Montague-street, L loomsluury, Aug. 1857. 